\title{
Mass Media Exposure and its Impact on Fertility: Current Scenario of Bangladesh
}

\author{
A. M. Fazle Rabbi* \\ Department of Applied Science, Bangladesh University of Textiles, Dhaka, Bangladesh
}

Received 16 November 2011, accepted in final revised form 27 March 2012

\begin{abstract}
On the way to reduce fertility rate of Bangladesh, mass media plays significant role to raise consciousness about the family planning program on general peoples. In this study the impact of mass media has been measured by the pattern of watching television, listening radio and reading newspaper. Using the proportional hazards model, the mass media exposure found to be a significant differential of fertility even after controlling the effects of contraception, place of residence, and mother's educational and employment status. This implies, by taking necessary steps, mass media can be used much more adequately to reduce fertility rate of Bangladesh.
\end{abstract}

Keywords: Fertility; Mass media exposure; Hazards model.

(C) 2012 JSR Publications. ISSN: 2070-0237 (Print); 2070-0245 (Online). All rights reserved. doi: http://dx.doi.org/10.3329/jsr.v4i2.8917 J. Sci. Res. 4 (2), 383-395 (2012)

\section{Introduction}

Since the independence, one of the major problems of Bangladesh is its population problem, i.e., the population size and rate of population increase. All of the governments focus on this problem and major success achieved in this sector in the last two decades when Bangladesh gained a remarkable demographic transition [1]. The total fertility rate declined from about 6.3 in the early 1970s to 3.3 in the mid 1990s [2]. Fertility then declined at around 3.3 births per woman for most of the 1990s, which was followed by another noteworthy decline in 2000s. The BDHS 2007 [2] indicates that the decline in fertility has continued during the last three years, reaching 2.7 births per woman. The process mainly used to stop the increasing fertility rate is the proper utilizations of mass media; by upholding the demerits of increased populations and its consequences. Hence, these are the easiest and probably the only way to communicate with the people to create awareness about issues of public health.

*E-mail: amfrabbi@hotmail.com 
Media influence or media effects are used in media studies, psychology, communication theory and sociology to refer to the theories about the ways in which mass media affect how their audiences think and behave. It introduces a great opportunity to increase the level of living, social welfare, economical solvency [3]. Social scientists have made efforts to integrate the study of the mass media as an instrument of controlling the study of political and economic developments in the Afro-Asian countries. When there is a heavy emphasis on the expansion of mass media in developing societies, the penetration of a central authority in the daily consciousness of the mass media has to overcome profound resistance [4]. Television, radio, and print media have frequently been mobilized to promote family planning, immunization, and a number of other services and behaviors. These efforts have included both short-term and long-term information, education, and communication (IEC) campaigns, social marketing, as well as entertainment cum education programs that have used the appeal of entertainment in an attempt to show individuals how they can live safer, healthier, and happier.

We may have a profile of determinants of fertility in Bangladesh. Early marriage is still a problem in Bangladesh; due to lack of consciousness. Many newly married couple does not use any contraception methods; due to lower women education rate and lower women employment rate, the natural barrier to decline fertility does not work prominently; due to some old mentality and socio-economical belief, gender preference is still present [5]. Without huge campaign regarding public health related programs in mass media, these situations cannot be overcome by any country. In Bangladesh; advertisements, dramas, documentaries have been used to make the people conscious about the population problem. It was fruitful for fertility scenario, because in modern context not only the family planning programs, but also various social dramas, movies (related to consequences of mass population) are also very motivational to change fertility behavior; as general people are influenced by those media culture and get precise ideas about smaller family norm.

\section{Context of the Study: Mass Media and Fertility}

In the last few decades, socio-economical condition changed with a rapid speed. Even at the beginning of 1990s, television was not available in many houses of Bangladesh (but many houses have radio). The number of radio listeners decreased in late 1990 and early 2000, but after that with the starting of FM radio stations, it became a new era in Bangladesh for radio. Most of the previous studies have been made on the basis of listeners of radio program about population problem, health topics and their fertility behavior (i.e. number of children they are having). Television becomes a common item in all household of Bangladesh in the last decade [6].

Several empirical studies have confirmed that mass media campaigns have effects at different stages in the process of behavior changes. Previous studies showed the significant impact of mass media on fertility reducing by showing transition on family planning behavior. Mass media campaigns promoting family planning programs have 
been proved successful for Bangladesh [7, 8], Iran [9], India [10, 11], Mexico [12], Zimbabwe [13], Nepal [14, 15], Mali [16], Tanzania [17], Uganda [18] and Ghana [19].

Most of these previous studies focused on the impact of family planning programs (whether on television or radio or in print media) on fertility. Few of the previous researchers studied the impact of print media on fertility behavior [20]. It has been proved that, mass media may be influential in the diffusion of attitudes and knowledge about family planning (FP) along with the change in world views or value systems which indirectly affect fertility or social behavior [21]. The impact of family planning programs on current use of contraception was mentioned as determinant of fertility decline in previous studies [7]. It was also explored that; education, number of living children and current contraceptive use were important proximate determinant of exposure to any mass media family planning messages to fertility behavior [15]. Mass media influence couples to increase discuss among themselves about family planning behavior. For example, Tanzanian women exposed to a mass media were found to have more positive attitudes towards family planning and to discuss family planning with their spouses [17]. It is proved that mass media and social networks play important roles in disseminating contraceptive knowledge; women who are regularly exposed to mass media, or who have a wider social network, have more knowledge about contraceptives than their counterparts [22]. Few study explained mass media exposure as a determinant of fertility decline [23]; fertility in Ghana has fallen sharply in recent years with the rate of decline being one of the most rapid in Sub-Saharan Africa.

African countries draw interest of many scientists about their family planning behavior. The influences of multi-media Behavior Change Communication campaigns on women's and men's use of contraception and intentions to use contraception in target areas of Uganda have been examined in previous studies. Results indicated that exposure to BCC messages was associated with higher contraceptive intentions and use. While there was some evidence of bias of self-report, the pathways to behavior change appeared different for women and men [18]. Summary of the reviewed old research works about mass media and its impact on fertility and public health suggest that, television plays a multi-faceted role in shaping individual's decision-making procedures concerning both demographic events and public health interactions. To illustrate this, a model has been presented which demonstrates a 'sliding scale' of intent - but not impact - of various genres in order to understand the actual role of the media in shaping attitudes towards family size - either explicitly in terms of 'edutainment' or implicitly as a forms of normalization [24].

Mass media exposure and its effect on family planning in Bangladesh have been analyzed before and it reveals that both socioeconomic development policies and family planning programs with a special emphasis on mass media, especially radio may have a significant effect on contraceptive use in [8]. The impact of mass media in family planning program is also compared in another study with major objective to compare fertility scenario of urban and rural dwellers [7]. It was found that urban residence are more exposed and motivated to family planning programs than their rural counterparts. 
The presence of regional variation was also mentioned by previous researchers [28]. In another study, television was found to have a significant effect on fertility and contraceptive use both in the urban and rural women. The effect of radio and GOs/NGOs was insignificant among the rural women. However, exposure to mass media and education (except secondary) appears to have weak significant effects on fertility and strong on contraceptive use [29].

Thus, most of the previous studies explored the effect of mass media only from the frequencies of the respondents about their watching/listening of family planning program on television/radio and the impact was verified only for contraception. In this paper, we are trying to explore the total impact of mass media on fertility, without any intermediate terms. The basis of considering mass media exposure instead of family planning programs is, mass media exposure includes all the effects together- motivation from family planning campaign and the motivation from various programs, news articles that influence the audience/reader/exposed persons to take necessary steps to build family of small size.

\section{Data and Methodology}

The data utilized for this study is a secondary data extracted from the Bangladesh Demographic and Health Survey conducted in 2007 under the authority of the National Institute for population Research and Training (NIPORT) of the Ministry of Health and Family Welfare. The 2007 Bangladesh Demographic and Health Survey (BDHS) [2] is a nationally representative sample survey designed to provide information on basic national indicators of social progress including fertility, childhood mortality, contraceptive knowledge and use, maternal and child health, nutritional status of mothers and children, awareness of AIDS, and domestic violence. For analysis, the dependent variable is birth interval (up to fifth birth). Clearly, throughout an interval, women may either have a birth or be right censored at the time of the survey. Thus, censored cases require special treatment in estimating exposure time, and as such, ordinary regression procedures are not appropriate. Therefore, Cox proportional hazards model is used to assess the effect of mass media exposure and the other covariate on the timing of birth intervals. Abridge Life Table Technique [25] has been applied to find the parity progression rate in different birth orders. The objective of using Life table technique is to examine the extent to which the observed variations in fertility with respect to mass media exposure in Bangladesh could be explained in terms of the proportion of women of given parity who have another child and the timing of the next birth.

\section{Measurement of variables}

Dependent variable: From birth history data birth intervals are computed by subtracting date of marriage or date of birth of previous child from date of birth of index child. First to fifth birth intervals have been considered in this study as it covers most of the range of fertility experience in Bangladeshi women. 
Independent variable: The main interest of this study is to determine the impact of mass media on fertility (birth spacing), which is the main independent variable of the study. Few others important factors of demographic, socio-economic and healthcare facilities have been identified as explanatory variables on the basis of chi-square test and from the previous studies. They are mother's age at first marriage, mother's education and employment status, place of residence (urban/rural), contraception status. There are few more variables which showed significant bivariate relation with length of birth interval but due to avoid the problem of severe multicollinearity, only selected variables are used in the study; dropping variable technique has been used to select variables.

The variable mass media exposure has been constructed from the frequencies of reading newspaper, watching television and listening radio together. All of these frequencies have been coded in four classes, 'Not at all', 'Less than once a week', 'At least once a week', 'Al most every day'. They were coded as 0, 1, 2 and 3 respectively. To find out the mass media exposure all of these three indicators together have been taken into account, and the highest value of these three indicators is considered as the status of the respondent's mass media exposure. Suppose a respondent watch television at least once a week (2), never listen to radio (0), read newspaper less than once a week (1). Then his highest value in this indicator is 2 , that is, he is exposed at least once a week. Thus, highest weight is given to the highest amount of exposure to a particular indicator. In this way, very few persons are over-weighted as the number of all 3 or 2 is very few in the data. Thus, the final categories of the variable mass media exposure are as give in Table 1.

Table 1. Mass media exposure status.

\begin{tabular}{ll}
\hline Mass media exposure & Value of the indicators \\
\hline Not exposed & All the three indicators are zero \\
Lowest exposed & $\begin{array}{l}\text { The highest value of all three indicators is 1, i.e., exposed } \\
\text { less than once a week to any one or all of the indicators. }\end{array}$ \\
Moderately Exposed & $\begin{array}{l}\text { The highest value of all three indicators is 2, i.e., exposed at } \\
\text { least once a week to any one or all of the indicators. }\end{array}$ \\
Very often exposed & $\begin{array}{l}\text { The highest value of all three indicators is 3, i.e., very often } \\
\text { exposed to any one or all of the indicators. }\end{array}$ \\
\hline
\end{tabular}

Gender preference is constructed on the basis of the desire of the gender of the upcoming child. For those births where parents desired a particular child (either son or daughter) have been considered as birth with presence of gender preference. Mother's age at first birth is important criterion for fertility; it has been grouped for simplification. 


\section{Results}

The frequency distribution of mass media exposure according to indicators of mass media exposure status is presented in Table 2.

Table 2. Number of persons by mass media exposure in Bangladesh; BDHS-2007.

\begin{tabular}{lcc}
\hline Mass media exposure & Frequencies & Percentages \\
\hline Not exposed & 4119 & 37.5 \\
Lowest exposed & 4119 & 8.8 \\
Moderately exposed & 2045 & 18.6 \\
Very often exposed & 3867 & 35.2 \\
\multicolumn{1}{c}{ Total } & 10996 & 100.0 \\
\hline
\end{tabular}

The percentages distribution for watching television, listening radio, reading newspaper; contraception status/education level/employment status of respondents with respect to mass media exposure are given appendices. From BDHS 2007 [2], 23.5\% of the respondents have radio, $30.6 \%$ have television. Only $11.6 \%$ of the total respondents have both radio and television. The mean and median for the last birth interval for FP listener on Radio are 48.32 months and 40.57 months; those who heard FP on television have birth interval with mean and median of 53.21 months and 45 months and for print media the mean and median is 56.21 months and 50 months, respectively. The comparisons between all three media in terms of number of births are shown in Appendix.

A total of four models have been considered in multivariate analysis. The hazard ratios of all the models are shown in Table 3. The results in Model 1 indicate that the effect of mass media exposure has a statistically significant effect on length of birth intervals. Chance of terminating birth intervals decrease by $6.8 \%$ in respondents who are lowest exposed to mass media than the reference group, i.e., those who are not exposed to mass media at all. This probability decreased monotonically to next groups. Those who are exposed to mass media very often, they have $17.5 \%$ increased birth intervals than those who are not exposed to mass media at all. The result may be seemed to be extra-weighted but, in the next models, the basis of these results is proved much precisely. In Model 2, the effect of mass media exposure on length of birth intervals has been modestly increased in the presence of the control for contraception. After controlling the effect of contraception, in model 2, it has been found that the lowest exposed group has $7.5 \%$ increased birth intervals than those who are not exposed at all. In previous model (Model 1 ), this hazard ratio was 0.932 , whereas in model 2 it is 0.925 . Moderately exposed group has $12.1 \%$ increased birth intervals and often exposed group has $18.9 \%$ increased birth intervals than those who are not exposed at all. 
A. M. Fazle Rabbi, J. Sci. Res. 4 (2), 383-395 (2012) 389

Table 3. Hazards Models of the risk of overall birth interval: Bangladesh; BDHS-2007.

\begin{tabular}{|c|c|c|c|c|}
\hline $\begin{array}{l}\text { Demographic and socio- } \\
\text { economic characteristics }\end{array}$ & Model 1 & Model 2 & Model 3 & Model 4 \\
\hline \multicolumn{5}{|l|}{ Mass media exposure } \\
\hline \multicolumn{5}{|l|}{ Not exposed (ref) } \\
\hline Lowest Exposed & $0.932^{\dagger}$ & $0.925^{\dagger}$ & $0.929^{\S}$ & $0.955^{\S}$ \\
\hline Moderately Exposed & $0.888^{\S}$ & $0.879^{\dagger}$ & $0.887^{\dagger}$ & $0.906^{\dagger}$ \\
\hline Very often exposed & $0.825^{\S}$ & $0.811^{\dagger}$ & $0.832^{\dagger}$ & $0.868^{\dagger}$ \\
\hline \multirow{2}{*}{\multicolumn{5}{|c|}{$\begin{array}{l}\text { Mother's age at first } \\
\text { marriage }\end{array}$}} \\
\hline & & & & \\
\hline \multicolumn{5}{|l|}{$\leq 15$ (ref) } \\
\hline $16-19$ & & & $1.032^{\S}$ & $1.053^{\dagger}$ \\
\hline $20-24$ & & & 0.956 & 1.030 \\
\hline$\geq 25$ & & & $0.851^{\S}$ & 0.990 \\
\hline \multicolumn{5}{|l|}{ Contraception status } \\
\hline \multicolumn{5}{|l|}{ Never used (ref) } \\
\hline Used only folkloric & & $1.551^{\dagger}$ & $1.545^{*}$ & $1.559^{\dagger}$ \\
\hline Used traditional methods & & $1.174^{\S}$ & $1.180^{\dagger}$ & $1.198^{\dagger}$ \\
\hline Used modern method & & $1.137^{\S}$ & $1.140^{\dagger}$ & $1.165^{\dagger}$ \\
\hline \multicolumn{5}{|l|}{ Place of residence } \\
\hline \multicolumn{5}{|l|}{ Urban (ref) } \\
\hline Rural & & & $1.065^{\dagger}$ & $1.053^{\dagger}$ \\
\hline \multicolumn{5}{|l|}{ Gender preference } \\
\hline \multicolumn{5}{|l|}{ No (ref) } \\
\hline Yes & & & & $1.060^{\dagger}$ \\
\hline \multicolumn{5}{|l|}{ Mother's education } \\
\hline \multicolumn{5}{|l|}{ No education (ref) } \\
\hline Primary & & & & $0.960^{\dagger}$ \\
\hline Secondary & & & & $0.878^{\dagger}$ \\
\hline Higher & & & & $0.743^{\dagger}$ \\
\hline \multicolumn{5}{|l|}{ Mother's working status } \\
\hline \multicolumn{5}{|l|}{ Not employed (ref) } \\
\hline Employed & & & & $0.852^{\S}$ \\
\hline
\end{tabular}

Note: Reference category is denoted by (ref). Significance: ${ }^{\dagger} p<0.01,{ }^{\S} p<0.05,{ }^{*} p<0.1$.

The most amazing result was obtained for contraception status. One of the interesting findings of this study is that, the birth interval of any order are likely to be higher among those women who ever used any contraceptive methods, compared to those who never used of any contraceptive methods. Though it is an unexpected and particular result but it may occur due to the fact that those women who are ever users are young newly married 
and want to keep their family size small. Since at young age they are more fertile, so birth interval may be shorter. On the other hand vast majority of the never user are adolescent and their marriage to first birth interval is naturally higher due to adolescent subfecundity. Similar results were obtained in the previous studies [26]. However, this needs further investigation after controlling use started before index child conception.

In model 3, mass media exposure is highly significant, the odds increased slightly than the model 2 . Here the hazard ratios are $0.929,0.887$ and 0.832 respectively for lowest exposed, moderately exposed and often exposed group. Age at first marriage plays an important role on parity progression in terms of length of birth intervals and having higher number of children [27]. In Bangladesh, the legal age for women to get married is 18 years and for male this age is 21 years. However, practically the scenario is much more different in rural areas, even sometimes in urban areas, too. In this study, the reference group was women who get married less than 15 years. Next early married group (16-19) years have comparatively shorter birth interval than reference group; they have $3.2 \%$ shorter birth interval than reference group. There may be two possible reasons behind thisadolescent's sub-fecundity or abortion of first birth. Many Demographers claimed the second as a principle reason of lower fertility for this age group, as it's a common problem in rural areas of Bangladesh [28]. More in-depth analysis is needed to reach to a generalized reason. Women who get married between 20 to 24 years, have $4.4 \%$ increased birth intervals than reference group while women who get married 25 or later have $14.9 \%$ increased birth intervals than reference group. The higher birth intervals for later married group reflect their decision about family planning. Place of residence is another important differential of fertility, the rural people are found to have shortened birth intervals than their urban counterparts. In Model 3, place of residence is positively associated with fertility. Rural women are 1.065 times more likely to terminate birth intervals than that of their urban counterparts.

In full model (Model 4), gender preference, mother's educational status and employment status is included along with previous variables. Like the previous models, in Model 4, mass media exposure is highly significant covariate of birth interval. In this model; lowest exposed mothers have $4.5 \%$ longer birth intervals than not exposed mother; moderately exposed mothers have $9.4 \%$ increased birth intervals than not exposed mothers and often exposed mothers have $13.2 \%$ increased birth intervals than that of not exposed mothers. This significantly proves the impact of mass media exposure on length of birth interval, i.e., fertility.

For lack of education and socio-economical backgrounds, still a son is much more preferable for many newly married couple. A son can earn money when he is matured, he can take care of the parents when they are aged, he can secure the real-estate properties/can increase the properties; a daughter would leave the family when she get married, she can't do the previously explained works which might be done by a son- for these reasons a huge portion of the society expect son over daughter [5]. Again, in rural areas, even sometimes in urban areas; mothers are neglected if they give birth of a 
daughter. Moreover, in some place of Indian subcontinent, mothers, who don't have any son, are hesitated by the society, by the father-in-law, mother-in-law; even sometimes it cause the possible divorce in many families of Indian subcontinent. All of these stuffs create the gender preference, which sometimes make the mothers to expect a son as a child. In Model 4, gender preference is positively associated with length of birth intervals. The birth interval without gender preference (reference group) is found to be larger than that of presence of gender preference. The reason may be the mentality of parents and traditional beliefs which switched them to have earlier child for preferred gender, either son or daughters. Gender preference showed significant impact on fertility in previous study, which was similar to the findings of current study [30].

Educated and employed mothers are usually favorable to small family norm. In many study it has been proved [31] that higher educated mothers are conscious about small family norm because it is harder to maintain and take good care of a large family in question of health related topics. Moreover educated mothers are conscious about demerits of increased population, too. Similarly, employed mother always seek for less number of children, as it become harder for them to take good care of them after maintaining the job. After controlling the effects of all other factors, primary educated mothers have $4 \%$ increased birth intervals than non-educated mothers; secondary educated mothers have $12.2 \%$ increased birth intervals than non-educated mothers and higher educated mothers have $25.7 \%$ increased birth intervals than non-educated mothers. This is another impact of mass media, because in last few decades GOB tried hard and soul to diminish illiteracy. So many program, drama, even some cartoon program were run in the television to make the people understand the benefit of women education. Employed mothers are 0.852 times less likely to terminate their birth intervals than that of unemployed mothers, similar results was obtained in previous studies [32]. These three factors motivate one another in a cyclic way: mass media exposure encouraged the women and their parents to get their daughter educated; educated women always want to be self dependent, they do not like to be burden to others, tried to own their economical freedom; which turn them to obtain empowerment (employed, obviously); employed mother always seek for less children for her convenience which made the ultimate reduction in fertility level. So, if we give emphasize from the route level to get women educated, motivate them to leave the old mentality of gender preference, can employ them to suitable jobs, it must should be reflected in fertility scenario.

\section{Life table approach}

The impact of mass media is already found to be significant for length of birth intervals from Cox proportional hazards models. In this section, Life Table Technique [25] has been applied to find the parity progression rate in different birth orders. The objective of using Life table technique is to examine the extent to which the observed variations in fertility with respect to mass media exposure in Bangladesh could be explained in terms of 
the proportion of women of given parity who have another child and the timing of the next birth. The brief results of all 20 life tables are summarized in the following table.

Table 4. Summary measures for birth intervals by level of mass media exposure; BDHS-2007.

\begin{tabular}{|c|c|c|c|c|c|c|}
\hline \multirow{2}{*}{$\begin{array}{l}\text { Mass media } \\
\text { exposure }\end{array}$} & \multirow{2}{*}{$\begin{array}{l}\text { Summary } \\
\text { measures }\end{array}$} & \multicolumn{5}{|c|}{ Birth order } \\
\hline & & First & Second & Third & Fourth & Fifth \\
\hline \multirow{5}{*}{$\begin{array}{l}\text { Not } \\
\text { exposed }\end{array}$} & $\mathrm{B}_{20}$ & 0.3568 & 0.1221 & 0.0962 & 0.1045 & 0.0984 \\
\hline & $\mathrm{B}_{40}$ & 0.6885 & 0.5868 & 0.5484 & 0.5085 & 0.5022 \\
\hline & $\mathrm{B}_{60}$ & 0.8397 & 0.7881 & 0.7216 & 0.6685 & 0.6434 \\
\hline & Trimean (T) & 17.00 & 22.25 & 22.50 & 22.00 & 22.00 \\
\hline & Spread (S) & 22.00 & 18.00 & 17.00 & 18.00 & 17.00 \\
\hline \multirow{5}{*}{$\begin{array}{l}\text { Lowest } \\
\text { exposed }\end{array}$} & $\mathrm{B}_{20}$ & 0.3583 & 0.1005 & 0.0962 & 0.0907 & 0.0887 \\
\hline & $\mathrm{B}_{40}$ & 0.7077 & 0.5213 & 0.4555 & 0.4775 & 0.4527 \\
\hline & $\mathrm{B}_{60}$ & 0.8691 & 0.7489 & 0.6746 & 0.6459 & 0.5775 \\
\hline & Trimean (T) & 16.75 & 23.25 & 24.00 & 22.75 & 23.25 \\
\hline & Spread (S) & 21.00 & 19.00 & 21.00 & 18.00 & 16.00 \\
\hline \multirow{5}{*}{$\begin{array}{l}\text { Moderately } \\
\text { exposed }\end{array}$} & $\mathrm{B}_{20}$ & 0.3966 & 0.1260 & 0.0785 & 0.0755 & 0.0777 \\
\hline & $\mathrm{B}_{40}$ & 0.7225 & 0.5176 & 0.4226 & 0.4221 & 0.3710 \\
\hline & $\mathrm{B}_{60}$ & 0.8621 & 0.7125 & 0.5879 & 0.5835 & 0.4984 \\
\hline & Trimean (T) & 16.25 & 22.00 & 22.50 & 22.75 & 22.25 \\
\hline & Spread & 21.00 & 21.00 & 19.00 & 19.00 & 18.00 \\
\hline \multirow{5}{*}{$\begin{array}{l}\text { Very often } \\
\text { exposed }\end{array}$} & $\mathrm{B}_{20}$ & 0.3847 & 0.0999 & 0.0706 & 0.0813 & 0.0560 \\
\hline & $\mathrm{B}_{40}$ & 0.7341 & 0.4424 & 0.3713 & 0.3774 & 0.3666 \\
\hline & $\mathrm{B}_{60}$ & 0.8654 & 0.6579 & 0.5272 & 0.5239 & 0.4882 \\
\hline & Trimean (T) & 15.75 & 23.00 & 23.00 & 23.00 & 22.75 \\
\hline & Spread (S) & 19.00 & 22.00 & 20.00 & 20.00 & 18.00 \\
\hline
\end{tabular}

In life table analysis it has been found that length of marriage to first birth interval is almost same for all level of mass media exposed persons in 'BDHS 2007'. The trimean for marriage to first birth interval for non-exposed, lowest exposed, moderately exposed and often exposed mothers are 17 months, 16.75 months, 16.25 months and 15.75 months respectively. Thus, the trend is decreasing for marriage to first birth interval.

But, for all higher order births, the time of parity progression increase with more exposing to mass media. Say, for fourth birth, the Tukey’s trimean is 22 months, 22.75 
months, 22.75 months and 23 months, respectively for non-exposed, lowest exposed, moderately exposed and often exposed mothers. From the results, clearly, the proportion of mothers taking higher number of children decreases with more exposing to mass media. This result indicates the significant effect of mass media on length of birth intervals.

\section{Conclusion}

This paper investigated the effect of mass media exposure and some selected covariates on fertility. Among demographic variables, mother's age at first marriage and gender preference are found to have significant effect on length of index birth interval. From socio-economic factors, exposure status to mass media, place of residence, mother's education and working status, contraception status have significant impact on length of birth intervals.

Instead of counting only the impact of family planning programs, the overall impact of mass media on fertility had been considered in this study. To do that, the mass media exposure had been defined with a new index, where all three indicators of mass media (how frequently a respondent is watching television, how frequently he is listening to radio and how frequently he is reading newspaper) have been taken into account. In multivariate analysis all of the four models, mass media exposure is found to be significant differential of birth intervals. In full model when all other variables are controlled; lowest exposed mothers have $4.5 \%$ longer birth intervals than not exposed mother; moderately exposed mothers have $9.4 \%$ increased birth intervals than not exposed mothers and often exposed mothers have $13.2 \%$ increased birth intervals than that of not exposed mothers. Current study implies that contraception status is negatively related with fertility, contraceptive users have smaller birth intervals than non-users. Higher educated mother have higher birth interval (25.7\% increased birth interval then non-educated mothers in full model), employed mother have nearly $15 \%$ increased birth interval than unemployed mothers.

It had been discussed earlier that mass media does not work directly on fertility but by some intermediate terms. Though the scenario of women's education and employment status have been increased rapidly in Bangladesh, the current analysis still showed a poor relation between mass media and those intermediate variables. The Pearson's correlation coefficient between mass media exposure and women's education is 0.39 . Yes, the relation is a significant one, but the strength of the relation is still weak. The gender preference and mass media exposure are inversely related (that is normal, because as much one should exposed to mass media one should be less concerned about gender preference), but it also have a weak relation $(r=-0.031)$ which means, still there need improvement in both of these sectors to have full benefits.

The power of mass media is unbelievable. If we apply all of our will to change the fertility scenario in Bangladesh, the first step should be to create awareness to the general people. Without proper utilization of mass media, it is not possible to achieve success rapidly in population sector. Therefore, necessary communicative and effective steps 
should be taken to motivate people by mass media that can motivate the people for multidimensional purposes- to reduce fertility, to have well educated nation and economically developed nation.

\section{Appendix}
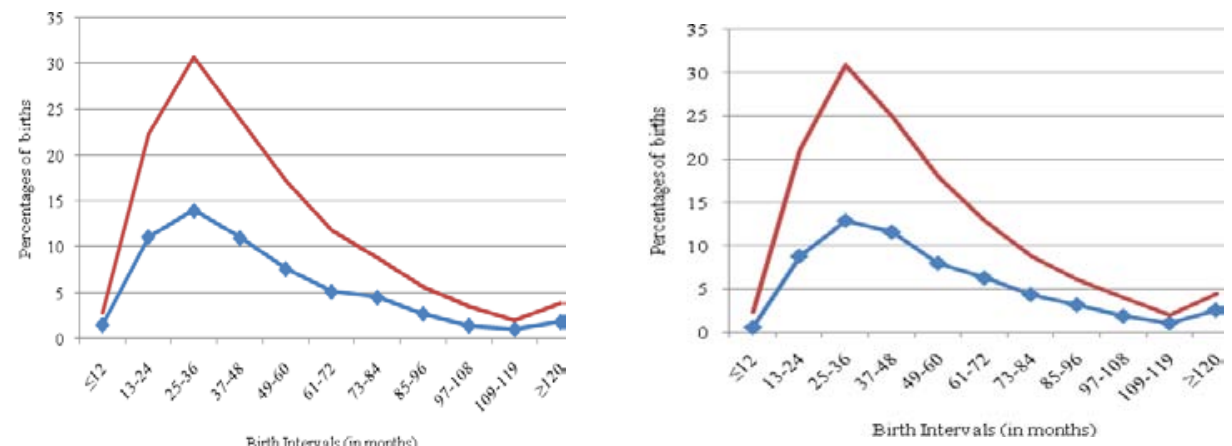

Fig. A1. Distribution of birth interval according to heard FP on (a) Radio (left), (b) TV (right). The upper (lower) curve of each figure is for not heard and heard, respectively.

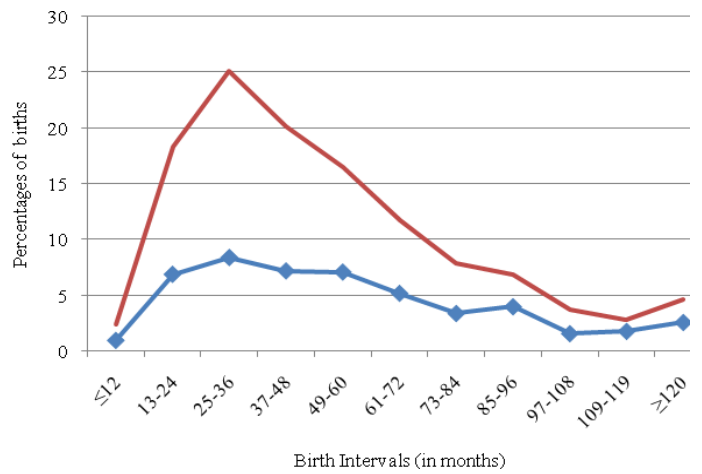

Fig. A2. Distribution of birth interval according to read FP on (a) print media.. The upper (lower) curve is for not read and read, respectively.

\section{References}

1. CPD-UNFPA Paper Series 23, Bangladesh’s population policy: Emerging issues and future agenda (March 2003).

2. Bangladesh Demographic and Health Survey 2007, National Institute of Population Research and Training (NIPORT) (Dhaka, Bangladesh, March 2009).

3. J. Mirza, Gomal University J. Res. 21, 5 (2005).

4. E. M. Rogers, P. W. Vaughan, Ramadhan M. A. Swalehe, N. Rao, P. Svenkerud, and S. Sood, Studies in Family Planning 27, 193 (1999). http://dx.doi.org/10.1111/j.1728-4465.1999.00193.x 
5. R. Bairagi, Int. Family Planning Perspectives 27 (3), 137 (2001). http://dx.doi.org/10.2307/2673835

6. A. M. Ahmed, Canadian J. Media Studies 5 (1), 50 (2009).

7. M. Kabir, M. Islam, and Amirul, J. Biosocial Sci. 32 (3), 411 (2000). http://dx.doi.org/10.1017/S0021932000004119

8. M. M. Islam and S. Hasan, J. Biosocial Sci. 32, 513 (2000). http://dx.doi.org/10.1017/S0021932000005137

9. S. S. Lieberman, Bull. Soc. Iranian Cult. Soc. Studies 5 (4), 149 (1972). http://dx.doi.org/10.1080/00210867208701431

10. J. M. Apte, IIPS newsletter 29 (4), 13 (1988).

11. M. S. Kulkarni, Health and Population: Perspectives and Issues 26 (2), 87 (2003).

12. R. Vernon, Family Planning Resume 2 (1), 82 (1978).

13. D. J. Adamchak, and M. T. Mbizvo, Studies in Family Planning 22 (5), 326 (1991). http://dx.doi.org/10.2307/1966687

14. M. Boulay, J. D. Storey, and S. Sood, J. Heal. Comm. 7 (5), 379 (2002).

15. J. S. Barber and W. G. Axinn, J. Marriage and Family 66 (5), 1180 (2004). http://dx.doi.org/10.1111/j.0022-2445.2004.00086.x

16. K. T. Thomas, G. Mohamadou, and S. Ilene, Studies in Family Planning 29 (3), 309 (1998). http://dx.doi.org/10.2307/172277

17. M. N. Jato, C. Simbakali, J. M. Tarasevich, D. N. Awasum, N. B. Clement and N. Edith, Int. Family Plan. Pers. 25 (2), 60 (1999). http://dx.doi.org/10.2307/2991943

18. N. Gupta, C. Katende, and R. Bessinger, Studies in Family Planning 34 (1), 19 (2003). http://dx.doi.org/10.1111/j.1728-4465.2003.00019.x

19. M. J. Hindin, D. L. Kincaid, O. M. Kumah, W. Morgan, and Y. M. Kim, Health Comm. 6 (2), 117 (1994). http://dx.doi.org/10.1207/s15327027hc0602_3

20. J. Williams, S. B. Sherwood, and J. Krishna, App. Comm. Res. 4 (1), 19 (1976). http://dx.doi.org/10.1080/00909887609360222

21. H. Kojima, Proc. IUSSP International Population Conference at Montreal, Canada (August 1993).

22. K. W. Cheng, J. Family Econ. Issues 32 (2), 257 (2011). http://dx.doi.org/10.1007/s10834-011-9248-1

23. P. Nicholas, Proc. 24th IUSSP General Conference at Salvador, Bahia, Brazil (August 2001).

24. S. Basten, Finnish Yearbook of Population Research 45, 67 (2010).

25. G. Rodriguez and J. N. Hobcraft, Illustrative analysis: Life Table analysis of birth intervals in Columbia. Scientific Reports, International Statistical Institute, London (1980).

26. N. Kamal, U. R. Saha, M. A. Khan, and R. Bairagi, J. Biosocial Sci. 39, 27 (2007). http://dx.doi.org/10.1017/S002193200500115X

27. K. Jeffrey and J. R. Udry, Demography 23 (1), 53 (1986). http://dx.doi.org/10.2307/2061407

28. M. M. Islam, U. Rob, and N. Chakrobarty, Genus 59 (3), 103 (2003).

29. M. A. Goni, Middle East J. Nursing 3 (4), 16 (2009).

30. R. Mace and R. J. Sear, J. Biosocial. Sci. 29, 499 (1997). http://dx.doi.org/10.1017/S0021932097004999

31. D. Beguy, Demographic Research 20 (7), 97 (2009). http://dx.doi.org/10.4054/DemRes.2009.20.7

32. T. Lappegård and M. Rønsen, Euro. J. Popul. 21 (1), 31 (2005). http://dx.doi.org/10.1007/s10680-004-6756-9 